\title{
Wilhelm von Humboldt, Journal parisien 1797-1798
}

\section{Sébastien Baudoin}

\section{(2) OpenEdition}

\section{Journals}

\section{Édition électronique}

URL : http://journals.openedition.org/studifrancesi/488

DOI : 10.4000/studifrancesi.488

ISSN : 2427-5856

\section{Éditeur}

Rosenberg \& Sellier

\section{Édition imprimée}

Date de publication : 1 avril 2015

Pagination : 157-158

ISSN : 0039-2944

\section{Référence électronique}

Sébastien Baudoin, «Wilhelm von Humboldt, Journal parisien 1797-7798 », Studi Francesi [En ligne], 175 (LIX | I) | 2015, mis en ligne le 01 avril 2015, consulté le 18 septembre 2020. URL : http://

journals.openedition.org/studifrancesi/488 ; DOI : https://doi.org/10.4000/studifrancesi.488

\section{Ce document a été généré automatiquement le 18 septembre 2020}

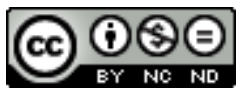

Studi Francesi è distribuita con Licenza Creative Commons Attribuzione - Non commerciale - Non opere derivate 4.0 Internazionale. 


\title{
Wilhelm von Humboldt, Journal parisien 1797-1798
}

\author{
Sébastien Baudoin
}

\section{RÉFÉRENCE}

WILHELM VON HUMBOLDT, Journal parisien 1797-1798, traduit par Elisabeth BEYER, présenté et annoté par Raymond Trousson, Paris, Honoré Champion, 2013, pp. 424.

1 Des deux frères von Humboldt, Wilhelm est sans doute le moins connu. Les travaux de naturaliste et la destinée d'explorateur d'Alexander ont quelque peu éclipsé le rayonnement intellectuel de son frère. Une récente exposition intitulée «Les Frères Humboldt - l'Europe de l'Esprit» (http://www.univ-psl.fr/default/EN/all/humboldt/) a contribué à rééquilibrer et réparer les injustices de l'Histoire et de la postérité en faisant des deux Berlinois des lumières intellectuelles qui brillent d'un éclat distinct, tout aussi grand l'un que l'autre. La réédition aux éditions Honoré Champion du Journal parisien de Whilelm von Humboldt, tenu de 1797 à 1799, permet de jeter un regard plus profond sur le moins connu des deux frères Humboldt.

2 L'annotation scientifique impeccable, précise et très utile du regretté Raymond Trousson permet de saisir tous les reliefs d'un esprit éclectique qui, séjournant en France en pleine période révolutionnaire alors que le pays sort quelque peu étourdi du grand traumatisme de 1789 et de la Terreur, s'immerge dans la vie culturelle des salons, des théâtres et des musées. Reprenant la traduction donnée par Elisabeth Beyer pour les éditions Actes Sud en 2001, cette réédition est dotée d'une introduction fournie qui fédère et analyse les nombreux pôles d'intérêt entre lesquels Wilhelm von Humboldt ne cesse de se déplacer au sein de son journal. Il s'y confie en effet bien moins qu'il n'y mène une réflexion en pointillés sur la nature des Français et de leur culture. Il n'est pas sans intérêt d'y percevoir le point de vue ouvert d'un allemand sur la France révolutionnée: Wilhem von Humboldt ne cache pas ses désillusions et ses réticences à l'égard de cette nation rivale qui le fascine autant qu'elle le déconcerte. Comme le 
rappelle Raymond Trousson, Humboldt tient ce journal «entre deux coups d'État», celui de 1797 et celui de 1799, parenthèse non pas enchantée mais tumultueuse où il fait le lien entre les sphères de la politique, des salons mondains et des arts, au premier rang desquels la littérature française, qu'il lit avidement d'un œil sagace et critique.

3 Wilhelm von Humboldt parait ainsi dur, parfois intraitable avec les Français, dont il esquisse, au fil des remarques, une forme de typologie: «il étudie l'altérité», note Raymond Trousson, pour établir ce qui fonde le caractère national français. Disparate, le journal d'Humboldt épouse les contours d'un esprit curieux et avide de culture, qui s'essaie très souvent à la métaphysique, relevant l'insuffisance des Français en la matière au gré des conversations de salons. Tantôt plongé dans les œuvres de Montaigne, Rousseau, Corneille ou Molière, cherchant l'essence du génie français dans ses représentants littéraires les plus illustres, il ne cesse d'exercer la sagacité de son esprit critique et se livre très fréquemment à l'exercice du portrait, en adepte des physionomies. Sieyès ou Bonaparte n'échappent pas à son coup de plume vivace. Spectateur investi au conseil des Cinq-Cents, dont il fait des compte rendus détaillés et analytiques, Wilhelm von Humbodlt fait de son journal un carnet de bord de sa réflexion et se montre surtout intéressé par la vie théâtrale de la capitale française. Les compte rendus de spectacles, les remarques sur le jeu, ses éloges des performances de Talma, deviennent de plus en plus importants au fil de la progression de son séjour parisien, la densité des remarques épousant l'intérêt grandissant qu'il éprouve pour cet art. La littérature subit le même sort, et si ses visites mondaines le laissent souvent sur sa faim alors qu'il rencontre les plus grands esprits politiques, artistiques ou littéraires de cette époque, les œuvres de Condillac, Mme de Staël, Condorcet ou Voltaire y sont détaillées par le menu, révélant un tropisme singulier de ce grand esprit méconnu.

L'intérêt majeur de cette édition scientifique du journal de Wilhelm von Humboldt est donc double: si elle fait ressortir de la pénombre un brillant esprit qui n'a rien à envier à son frère Alexander, elle présente un éclairage essentiel sur cette période trouble et peu étudiée, et dont la richesse mérite d'être davantage mise en valeur. C'est ce en quoi les notes éclairées de Raymond Trousson nous sont essentielles, remettant en contexte et en lumière événements et grandes figures aujourd'hui oubliées. Elles permettent ainsi à ce regard d'outre-Rhin, qui balaie de son spectre tous les aspects de la société parisienne de son temps, de briller d'autant plus, ajoutant à la force du témoignage aussi progermanique fût-il - la richesse d'une réflexion saisie à l'instant de sa germination. 